\title{
Implementasi Sistem Seleksi Pendaftaran Kelas Inkubasi di Yayasan Sedekah IImu Berbasis Website
}

\author{
Nurul Khasanah', Rachman Komarudin ${ }^{2}$ \\ 1,2STMIK Nusa Mandiri \\ 114002381@nusamandiri.ac.id, 2rachman.rck@nusamandiri.ac.id
}

\begin{abstract}
Yayasan Sedekah IImu is one of social institutions which connects business improvement and acceleration for young generation, UMKM and housewives through Marketing Online. Yayasan IImu Sedekah organizes an Incubation Class in a month. The registrants often face various obstacles in this class. The main one is about the registration system. It is still done manually so that the applicants who come from other countries are difficult to deal with this registration. These problems are solved by building an online registration system. The purpose of making this system is to make it easier for registrants to attend the incubation class. The method that the writer uses for programming is Systems Development Life Cycle (SDLC) model. The stages of the waterfall method are: needs analysis, design, coding, and testing. The authors create a website using Adobe Dreamweaver CS6 application using the programming language PHP and CSS. To collect the data, the writer uses observation, interview method and literature review. Through the online registration website, it will facilitate the registrants to register the incubation class easily. Moreover, it will also make easier for administrator to administer the data of incubation class.
\end{abstract}

Keywords: Incubation Class, Registration System, Website

\begin{abstract}
Abstrak: Yayasan Sedekah Ilmu adalah lembaga sosial yang hadir untuk menjadi jembatan peningkatan dan akselerasi bisnis bagi generasi muda, UMKM, dan ibu rumah tangga melalui Marketing Online. Untuk menjembatani hal tersebut, Yayasan Sedekah Ilmu menyelenggarakan Kelas Inkubasi selama satu bulan penuh. Kendala utama yang dihadapi oleh pendaftar dalam mengikuti Kelas Inkubasi adalah sistem pendaftaran yang masih dilakukan secara manual, sehingga pendaftar dari luar kota terkendala karena mereka harus menempuh jarak yang jauh untuk pendaftaran. Permasalahan tersebut diselesaikan dengan membangun sistem pendaftaran secara online. Tujuan dari pembuatan sistem ini adalah untuk memudahkan pendaftar dalam mengikuti kelas inkubasi. Metode yang penulis gunakan untuk pembuatan program adalah SDLC (Systems Development Life Cycle) model air terjun (waterfall). Dalam pembuatan website ini, penulis menggunakan aplikasi Adobe Dreamweaver CS6 dengan menggunakan bahasa pemrograman PHP dan CSS. Teknik pengumpulan data yang penulis gunakan adalah metode observasi, metode interview dan kajian pustaka. Dengan adanya website pendaftaran online untuk kelas inkubasi ini telah mempermudah pendaftar untuk mendaftar Kelas Inkubasi dan mempermudah admin untuk mengelola data-data yang berkaitan dengan Kelas Inkubasi.
\end{abstract}

Kata kunci: Kelas Inkubasi, Sistem Pendaftaran, Website by author and IJSE-Indonesian Journal on Software Engineering.

\section{A. PENDAhUluan}

UMKM mempunyai peran penting dan strategis dalam pembangunan ekonomi nasional. (BAPENNAS 2016) Selain berperan dalam pertumbuhan ekonomi dan penyerapan tenaga kerja, UMKM juga berperan dalam mendistribusikan hasil-hasil pembangunan. Walaupun peran UMKM sangat besar dalam menekan angka pengangguran, dan mengurangi angka kemiskinan, namun fakta di lapangan kehidupan para pelaku usaha sendiri tidak selalu berada dalam garis perekonomian yang sejahtera, itu terbukti dari produk yang mereka hasilkan tidak 
selalu memenuhi standar yang diinginkan pasar. Disamping kendala dalam hal produksi, sebagian pelaku usaha juga terkendala dalam aspek pemasaran. Sedangkan aspek pemasaran sangat penting peranannya dan merupakan ujung tombak dalam suatu bisnis atau usaha (Bibi Arfanly, Ma'mun Sarma 2016). Kendala dalam aspek pemasaran seperti itu tentunya akan berdampak pada nilai jual produk mereka walaupun produk yang dihasilkan sudah memenuhi standar yang diinginkan pasar namun karena kurangnya pemahaman dalam dunia marketing mereka terpaksa harus menjualnya dengan harga di bawah standar pasar.

Untuk mengatasi permasalahan yang dialami oleh wirausaha maka hadirlah Yayasan Sedekah IImu dengan program Kelas Inkubasi. Yayasan Sedekah IImu adalah lembaga sosial di Yogyakarta yang memiliki tujuan untuk meningkatkan kualitas UMKM di Indonesia. Kelas Inkubasi adalah pelatihan dan pendampingan bisnis oleh Yayasan Sedekah IImu dalam aspek pemasaran untuk pelaku UMKM seluruh Indonesia khususnya dalam online marketing. Melalui program tersebut, pihak Yayasan berkeinginan agar kualitas UMKM di Indonesia semakin meningkat.

Dalam pelaksanaannya Yayasan Sedekah IImu mampu memberikan pendampingan kepada pelaku UMKM dalam hal pemasaran produk sehingga nilai jual produk terangkat. Namun, pelaku UMKM di luar kota Yogyakarta terkendala untuk mendaftar kelas dikarenakan jarak yang cukup jauh. Sistem pendaftaran yang masih manual membuat pendaftar harus menempuh jarak yang jauh untuk pendaftaran. Pendaftar luar kota Yogyakarta akan merasa sia-sia ketika sudah mendaftar langsung ke kantor tetapi terpaksa ditolak karena tidak memenuhi syarat pendaftaran.

Berdasarkan uraian di atas, penulis tertarik untuk membuatkan Sistem Seleksi Pendaftaran Kelas Inkubasi di Yayasan Sedekah Ilmu berbasis website. Dengan sistem ini, penulis berharap dapat memberikan kemudahan untuk pendaftar dalam melakukan proses pendaftaran Kelas Inkubasi di Yayasan Sedekah IImu.

\section{B. TINJAUAN PUSTAKA}

\section{Sistem Pendaftaran}

Sistem menurut Mulyadi dalam (Asmara, 2016) adalah sekelompok dua atau lebih komponen-komponen yang saling berkaitan (subsistemsubsistem yang bersatu untuk mencapai tujuan yang sama. Menurut Depdikbud dalam (Magdalena dan Rachman, 2017) "Pendaftaran adalah proses, cara, perbuatan mendaftar yaitu pencatatan nama, alamat dsb dalam daftar. Jadi, pendaftaran adalah proses pencatatan identitas pendaftar kedalam sebuah media penyimpanan yang digunakan dalam proses pendaftaran."

\section{Teknologi Website}

a. Website

Menurut Rahmat dalam (Yufita dan Andriani, 2016) menyatakan bahwa Website merupakan kumpulan dari halaman-halaman yang ditampilkan melalui media internet yang berisi informasi dalam bentuk teks, animasi, suara, gambar, dan atau gabungan dari keseluruhannya dapat bersifat statis maupun dinamis dan halaman-halaman tersebut membentuk serangkaian hubungan yang saling terkait

b. PHP

Menurut Kadir dalam (Sari 2017) mengemukakan bahwa "PHP merupakan suatu bahasa pemograman berbasis web yang menyatu dengan HTML dan dijalankan oleh server side."

c. MySQL Database

Menurut Sibero dalam (Sari 2017) mengemukakan bahwa "MySQL adalah suatu RDBMS (Relational Database Management System) yaitu aplikasi sistem yang menjalankan fungsi pengolahan data."

\section{ERD}

Menurut Indrajani (2015:17) menyimpulkan bahwa :

Entity Relational (ER) Modelling adalah sebuah pendekatan top-bottom dalam perancangan basis data yang dimulai dengan mengidentifikasikan data-data terpenting yang disebut dengan entitas dan hubungan antara entitas-entitas tersebut yang digambarkan dalam suatu model. Karena terdapat keterbatasan pada ER Model, maka terdapat pengembangan penambhan konsep semantik pada ER yang disebut dengan Enchanced Entity Relational (EER) Model. Komponen yang digunakan dalam merancang ERD (Indrajani, 2015:12) antara lain; 
1. Entitas merupakan data inti yang akan disimpan.

2. Atribut merupakan kolom data yang disimpan.

3. Atribut Kunci Primer merupakan kolom data yang nilainya menjadi data utama.

4. Atribut Multi Nilai merupakan kolom data yang dapat memiliki nilai lebih dari satu.

5. Relasi merupakan hubungan antar entitas.

6. Asosiasi merupakan penghubung antara relasi dengan entitas, dimana di kedua ujungnya memiliki multiplicity kemungkinan jumlah pemakaian.

\section{Struktur Navigasi}

Menurut Binanto dalam (Indriyanti dan Rapiyanta, 2014)ada 4 struktur dasar navigasi, yaitu:

1. Linear yaitu pengguna melakukan navigasi secara berurutan, dari frame atau byte informasi yang satu ke lainnya.

2. Hierarkis, yaitu pengguna melakukan navigasi di sepanjang cabang pohon atau struktur alur yang sudah ditentukan.

3. Non-Linear, yaitu pengguna melakukan navigasi secara bebas, tanpa terikat pada jalur yang sudah ditentukan sebelumnya

4. Composit, yaitu pengguna melakukan navigasi secara bebas, terkadang dibatasi presentasi linear informasi penting atau pada data yang paling terorganisasi secara logis pada suatu hierarki atau struktur.

\section{BackBox Testing}

Menurut Rusadi dalam (Sintawati, Sari, 2017) mengemukakan bahwa "Black-box testing adalah metode pengujian perangkat lunak yang tes fungsionalitas dari aplikasi yang bertandatangan dengan struktur internal atau kerja. Menggunakan deskripsi eksternal perangkat lunak, termaksud spesifikasi persyaratan, dan desain untuk menurunkan uji kasus".

\section{METODE PENELITIAN}

Metode pengembangan perangkat lunak yang penulis gunakan adalah menggunakan SDLC (Systems Development Life Cycle) model air terjun (waterfall). Tahapan tahapan dari sistem ini menurut Sukamto dan Shalahuddin (2014:26) sebagai berikut :

1. Analisis

Langkah pertama setelah penulis mendapatkan objek penelitian, penulis melakukan perancangan sistem yaitu, analisis database. Dalam analisis database ini penulis menentukan tabel apa yang dibutuhkan. Setelah proses analisis selesai, tahapan selanjutnya adalah desain.

2. Desain

Pada tahapan ini desainer bertugas untuk membuat tampilan website secara keseluruhan, termasuk untuk warna, font, tema yang digunakan. Setelah proses ini selesai, tahapan selanjutnya adalah koding.

3. Koding

Tahapan koding merupakan inti dari sebuah sistem karena sistem tidak akan berjalan tanpa adanya koding. Pada proses ini yang terlibat adalah seorang programmer. Seperti yang penulis ketahui, koding itu terbagi menjadi dua jenis yaitu bersifat client side scripting dan server side scripting. Bedanya pada client side scripting script dapat berjalan pada sisi client atau yang lebih dikenal dengan istilah browser, seperti bahasa HTML CSS dan JavaScript. Sedangkan server side scripting adalah script hanya berjalan pada sisi server, seperti bahasa PHP, ASP, JSP dan sebagainya.

4. Testing

Setelah program atau koding selesai, maka dilakukan pengujian untuk memastikan apakah program yang telah dibuat sesuai dengan apa yang telah di rancang sebelumnya dan untuk memastikan agar program tidak terjadi error. Jika terjadi error pada bagian sistem, maka program akan dikembalikan kepada tahapan sebelumnya yaitu pada bagian koding. Namun jika error menunjukan pada sisi desain website, seperti tampilan menjadi berantakan dan lain sebagainya. Maka program akan dikembalikan ke tahapan yang kedua yaitu di bagian desain, kemudian jika selesai maka lakukan pengujian kembali sampai sistem yang dibuat lolos dari tahap pengujian. 
IJSE - Indonesian Journal on Software Engineering, Vol.6, No. 1, Juni 2020, 126-132 pISSN: 2461-0690 I elSSN: 2714-9935

D. HASIL DAN PEMBAHASAN

a. Perancangan Sistem

Perancangan basis data menghasilkan pemetaan tabel-tabel yang digambarkan dengan Entity Relationship Diagram (ERD) dan Logical Record Structure (LRS).

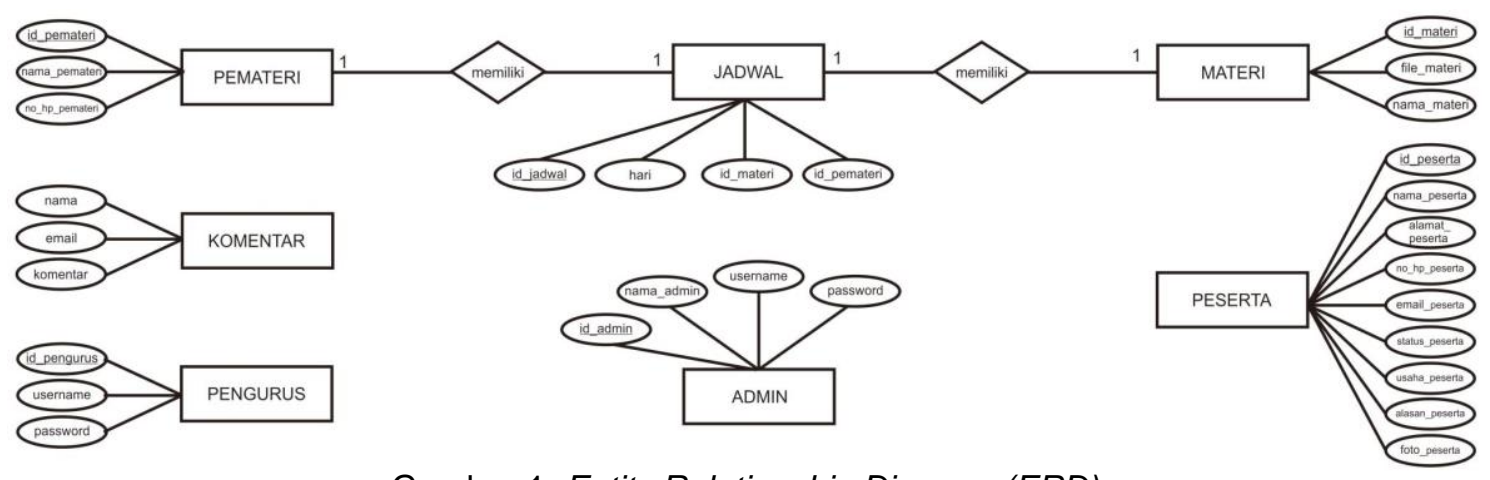

Gambar 1. Entity Relationship Diagram (ERD)

\begin{tabular}{|l|l|l|l|}
\hline \multicolumn{1}{|c|}{ sedekah_ilmu pemateri } & 1 & \multicolumn{1}{|c|}{ sedekah_ilmu jadwal } \\
\cline { 1 - 1 } $\begin{array}{l}\text { id_pemateri : varchar (5) } \\
\text { nama_pemateri : varchar (30) } \\
\text { no_telp_pemateri : varchar (10) }\end{array}$
\end{tabular}

\begin{tabular}{|c|c|}
\hline sedekah_ilmu komentar & sedekah_ilmu admin \\
\hline $\begin{array}{l}\text { nama : varchar }(30) \\
\text { email : varchar }(30) \\
\text { komentar : varchar }(100)\end{array}$ & $\begin{array}{l}\text { id_admin : int (1) } \\
\text { nama_admin : varchar (30) } \\
\text { username : varchar }(10) \\
\text { password : varchar }(10)\end{array}$ \\
\hline
\end{tabular}

\begin{tabular}{l}
\hline sedekah_ilmu pengurus \\
\hline id_pengurus : varchar (5) \\
username : varchar (10) \\
password : varchar (40)
\end{tabular}

sedekah ilmu peserta

id peserta : int (5)

nama peserta : varchar $(30)$

tgl_lahir_peserta : date

alamat_peserta : varchar (30)

no_telp_peserta : varchar (13)

email_peserta : varchar (40)

usaha_peserta : varchar (20)

alasan peserta : varchar $(100)$

foto peserta : varchar (100)

status peserta : varch

Gambar 2. Logical Record Structure (LRS)

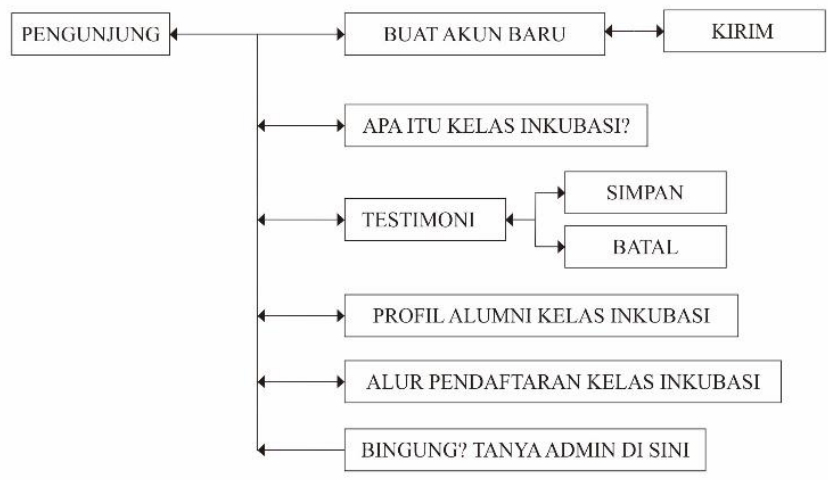

Gambar 3. Struktur Navigasi Pengunjung 
b. Implementasi pada website

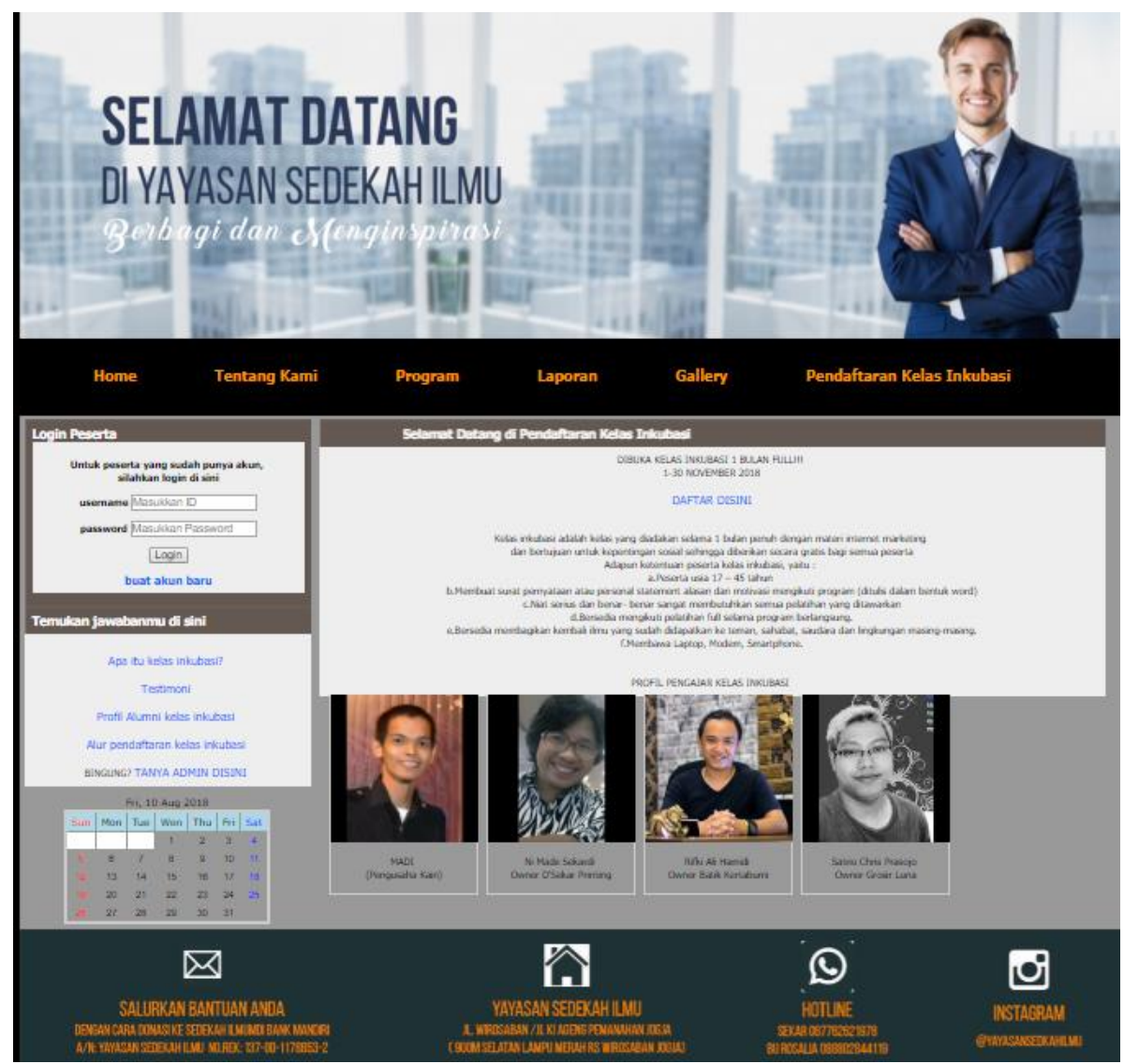

Gambar 4. Halaman Awal Pendaftaran Kelas Inkubasi

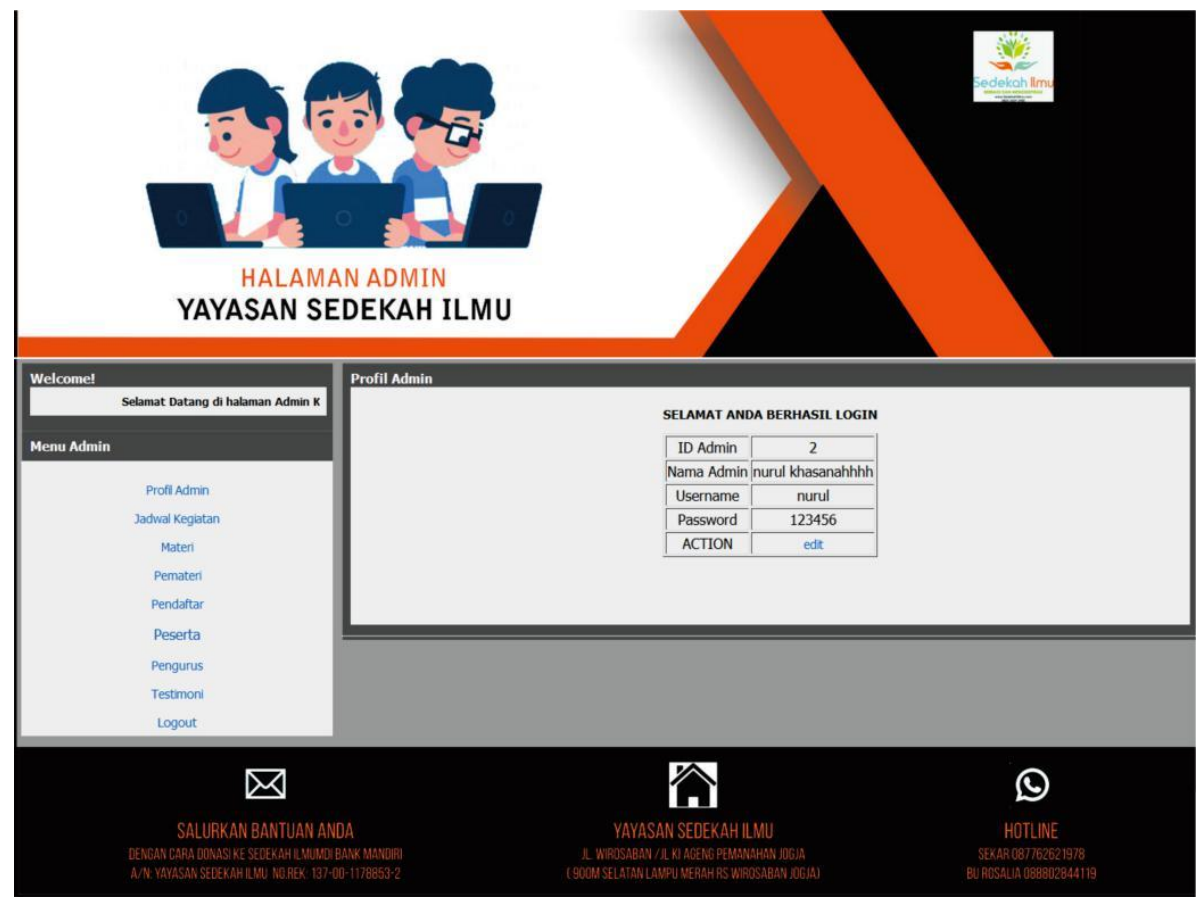

Gambar 5. Halaman Admin 


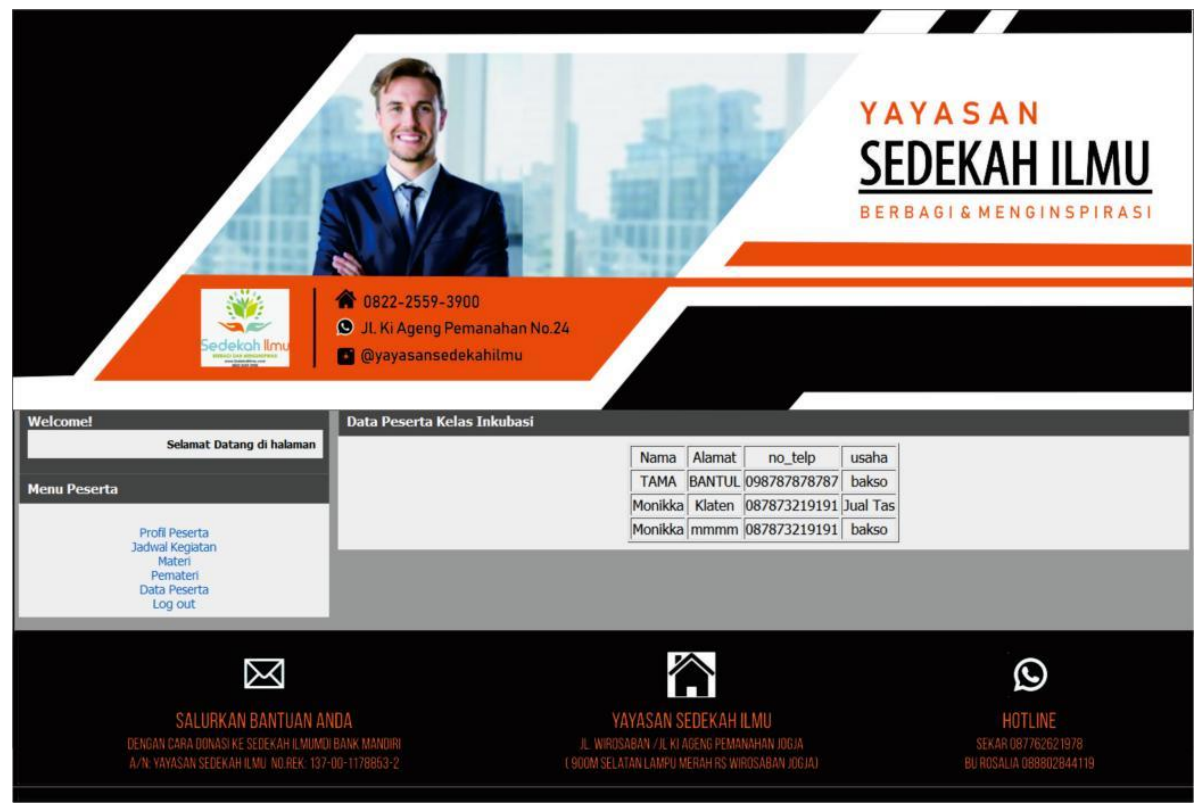

Gambar 6. Halaman Peserta

c. Testing

Tabel 1. Black box testing pendaftaran

\begin{tabular}{|c|c|c|c|c|c|}
\hline No & Skenario & Test case & $\begin{array}{l}\text { Hasil yang } \\
\text { Diharapkan }\end{array}$ & $\begin{array}{c}\text { Hasil } \\
\text { Pengujian }\end{array}$ & Kesimpulan \\
\hline 1 & $\begin{array}{l}\text { Nama, tanggal lahir, } \\
\text { alamat, no telepon, } \\
\text { email, usaha, alasan } \\
\text { dan foto tidak diisi } \\
\text { kemudian klik tombol } \\
\text { daftar }\end{array}$ & $\begin{array}{l}\text { Nama : (kosong) } \\
\text { tanggal lahir: } \\
\text { (kosong) } \\
\text { alamat: (kosong) } \\
\text { no telepon: (kosong) } \\
\text { email: (kosong) } \\
\text { usaha: (kosong) } \\
\text { alasan: (kosong) } \\
\text { foto: (kosong) }\end{array}$ & $\begin{array}{l}\text { Sistem akan } \\
\text { menolak untuk } \\
\text { menyimpan } \\
\text { dan } \\
\text { menampilkan } \\
\text { "Data tidak } \\
\text { boleh kosong" }\end{array}$ & $\begin{array}{l}\text { Sesuai } \\
\text { Harapan }\end{array}$ & Valid \\
\hline 2 & $\begin{array}{l}\text { Nama, tanggal lahir, } \\
\text { alamat, no telepon, } \\
\text { email, usaha, alasan } \\
\text { dan foto salah satu } \\
\text { tidak diisi kemudian } \\
\text { klik tombol daftar }\end{array}$ & $\begin{array}{l}\text { Nama : (data) } \\
\text { tanggal lahir: } \\
\text { (kosong) } \\
\text { alamat: (kosong) } \\
\text { no telepon: (kosong) } \\
\text { email: (kosong) } \\
\text { usaha: (kosong) } \\
\text { alasan: (kosong) } \\
\text { foto: (kosong) }\end{array}$ & $\begin{array}{l}\text { Sistem akan } \\
\text { menolak untuk } \\
\text { menyimpan } \\
\text { karena salah } \\
\text { satu data tidak } \\
\text { diisi dan } \\
\text { menampilkan } \\
\text { "Data tidak } \\
\text { boleh kosong" }\end{array}$ & $\begin{array}{l}\text { Sesuai } \\
\text { Harapan }\end{array}$ & Valid \\
\hline 3 & $\begin{array}{l}\text { Nama, tanggal lahir, } \\
\text { alamat, no telepon, } \\
\text { email, usaha, alasan } \\
\text { dan foto diisi } \\
\text { kemudian klik tombol } \\
\text { daftar }\end{array}$ & $\begin{array}{l}\text { Nama : (data) } \\
\text { tanggal lahir: (data) } \\
\text { alamat: (data) } \\
\text { no telepon: (data) } \\
\text { email: (data) } \\
\text { usaha: (data) } \\
\text { alasan: (data) } \\
\text { foto: (data) }\end{array}$ & $\begin{array}{l}\text { Sistem akan } \\
\text { menerima } \\
\text { untuk } \\
\text { menyimpan } \\
\text { dan data akan } \\
\text { masuk ke } \\
\text { tabel pendaftar } \\
\text { yang dikelola } \\
\text { oleh admin. }\end{array}$ & $\begin{array}{l}\text { Sesuai } \\
\text { Harapan }\end{array}$ & Valid \\
\hline
\end{tabular}




\section{E. KESIMPULAN}

Berdasarkan penjelasan yang dipaparkan di bab-bab sebelumnya, maka dapat ditarik kesimpulan sebagai berikut :

1. Website ini dapat mempermudah pendaftar untuk melakukan pendaftaran kelas inkubasi sehingga pendaftar tidak harus datang langsung ke Yayasan Sedekah IImu untuk mendaftar program kelas inkubasi.

2. Website ini dapat mempermudah admin dalam mengelola data-data yang berkaitan dengan Kelas Inkubasi, antara lain data pendaftar, data peserta diterima, data peserta ditolak, jadwal kelas, data pemateri dan data materi, data testimoni dan data pengurus.

3. Website ini dapat mempermudah pengurus untuk melihat laporan data peserta.

\section{REFERENSI}

Asmara, Rini. 2016. "Sistem Informasi Pengolahan Data Penanggulangan Bencana Pada Kantor Badan Penanggulangan Bencana Daerah (Bpbd) Kabupaten Padang Pariaman." 3(2). Retrieved From Http://Ejurnal.Jayanusa.Ac.Id/Index.Php/J-Click/Article/View/28

Bapennas. (2016). Penguatan Umkm Untuk Pertumbuhan Ekonomi Yang Berkualitas. Warta Kumkm, 5(1), 1-35. $\quad$ Retrieved From Https://Www.Bappenas.Go.Id/Files/8014/8116/6753/Warta_Kumkm_2016_Vol_5_No_1.P df

Arfanly Bibi, Ma'mun Sarma, Dan Muhammad Syamsun Mahasiswa. 2016. "Peran Entrepreneurial Marketing Dalam Peningkatan Kinerja Pemasaran Pada." 11(2). Retrieved From : Https://Journal.Ipb.Ac.Id/Index.Php/Jurnalmpi/Article/View/15288

Indrajani. 2015. Database Design (Case Study All In One). Jakarta: Elex Media Komputindo Indriyanti, \& Paulus Tofan Rapiyanta. 2014. "Perancangan Sistem Informasi Pendaftaran Pelatihan Pada Balai Latihan Kerja Bantul." : 295-302. Retrieved From Http://Seminar.Bsi.Ac.Id/Knist/Index.Php/Knist-2017/Article/View/322/0

Lena, Magdalena., \& Abdul Rachman. 2017. "Sistem Seleksi Menggunakan Metode Simple Additive Weighting ( Saw ) Pada Smk Miftahul Huda Ciwaringin." 7(1): 38-49. Retrieved From Http://Www.Jurnaldigit.Org/Index.Php/Digit/Article/View/14

Sintawati, Ita Dewi, Adika May Sari (2017). "Perlengkapan Tidur Berbasis Web." 19(2): 127-30. Retrieved From Http://Ejournal.Bsi.Ac.Id/Ejurnal/Index.Php/Paradigma/Article/View/2331/1624

Sari, Adika May. 2017. "Aplikasi Situs Web Penjualan Hijab Online.” 19(2): 113-17. Retrieved From Https://Ejournal.Bsi.Ac.Id/Ejurnal/Index.Php/Paradigma/Article/View/2290

Sukamto, Dan M. Salahuddin. 2014. Rekayasa Perangkat Lunak. Bandung: Informatika

Yufita, Anik Andriani. 2016. "Sistem Informasi Dan Promosi Berbasis Web Pada Family Mebel Magelang." 5(1): 1-6. Retrieved From Https://Repositor.Bsi.Ac.Id/Index.Php/Repo/Viewitem/4989. 